\title{
BIOMETRIC TECHNOLOGIES IN PASSENGER CLEARANCE
}

\author{
G. Költzsch \\ University of Applied Sciences Stralsund, Zur Schwedenschanze 15, 18435 Stralsund, Germany \\ E-mail: Gregor.Koeltzsch@gmx.de \\ Received 2006-06-27, accepted 2006-12-11
}

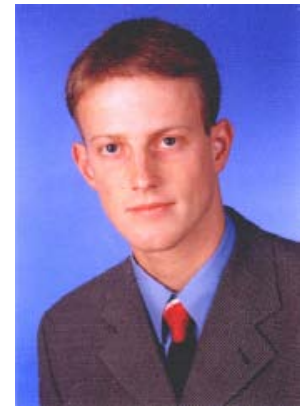

\section{Gregor KÖLTZSCH, MBA}

Date of birth: 1978

Education: 2002 diploma in business administration, Berufsakademie Berlin (Germany); 2004 Master of Business Administration, University of Applied Sciences Stralsund (Germany).

Professional experience: 2002 Bundesdruckerei Group, Assistant to the Managing Director; 2004 Consultant and Project Manager.

Research interest: Biometric technologies in security products and systems

Current Position: Bundesdruckerei GmbH, Business Development Manager.

\begin{abstract}
Having overcome a deep crisis, airlines and airports now report continuously growing passenger numbers, and existing infrastructural capacities at many airports reach their limit. At the same time, security requirements have been increasing since 2001, causing additional use of capacity and costs and declining efficiency.

Instead of expanding the capabilities of terminals and mobilizing more manpower for security activities, process optimization would be the smarter and more efficient way for airlines and airports to handle both passenger interests and security requirements. Biometric technologies may provide the technological basis for the optimization of these processes civil aviation security.

Biometric technologies are concerned with the measurement and evaluation of the physiological or behavioral characteristics of humans. In recent years, the security-oriented use of biometric technologies has become the most important field of research, although these technologies can also be used in a variety of other applications. Particularly, the verification and identification of human beings based on these characteristics have turned out to be the most important application of biometrics.

The author's research pursues the goal of optimizing civil aviation security processes by developing and implementing efficient processes based on innovative biometric technologies. The article analyzes the current status of the civil aviation market and industry, focusing on airports and airlines. Market and industry data is taken from IATA and ACI reports, as well as from commercial research papers. An introduction to biometric research and development is given in connection with civil aviation security. Based on the analysis, the passenger clearance process is suggested as an exemplary application field of biometrics in civil aviation security.
\end{abstract}

Keywords: biometrics, biometric technologies, security, security systems, aviation security, passenger clearance.

\section{Introduction}

The aviation industry experienced a deep crisis in the first years of the 21 st century. Although at first glance, the attacks of September 11 initiated the downturn, several other developments such as rising fuel prices and increasing competitive pressure by low cost carriers had already induced the negative development. In 2003, the outbreak of SARS and wars in the Middle East aggravated the situation. However, for the past two years, efforts at structural change by airports and airlines and positive market development have created a new growth trend. For example, many hubs and carriers profit from emerging markets in Asia and Eastern Europe, and the low cost carrier business strengthens the airports that have started doing business with low cost airlines ${ }^{1}$.

To understand the needs of airlines and airports as the core of the civil aviation business, we have to evaluate the current market figures, summarize the main influence factors in the market, describe the essential needs of airports and airlines, and thus provide the assumptions for a technology-based process optimization approach.

\section{The civil aviation market and industry}

The traffic performance in international civil aviation grew $15 \%$ in 2004 and $7.6 \%$ in 2005,

\footnotetext{
1) Airports Council International. Annual report 2004, Geneva 2005, p. 3 .
} 
measuring the amount of passenger kilometers. This indicates that the civil aviation industry has started to recover from the 2001 to 2003 crisis [11]. In the first quarter of 2006, international civil aviation continued to grow $6 \%$, primarily supported by strong world economic growth ${ }^{2)}$. IATA forecasts that 2.3 billion passengers and 45 million tons of freight will be transported annually by 2007 and that the turnover of the airline industry will rise from USD 379 billion in 2004 to USD 477 billion in 2007 at an average annual growth rate of $7.9 \%{ }^{3)}$. The growth will continue over the coming years. Booz Allen Hamilton forecasts an average annual market growth of 4-6 \% in the mid-term [16]. Deutsche Bank Research forecasts an annual growth of $5 \%$ in civil passenger transport and $6 \%$ in civil freight transport over the next 20 years. Civil aviation will profit from international economic growth, the rising integration of international markets, and global trends like outsourcing and offshoring. Furthermore, the strong growth of tourism originating in developing and newly industrializing countries like China will boost civil aviation [13].

Consequently, it can be predicted that passenger numbers will triple within the next 25 years, and terminal capacities will reach their limits. The first signs of capacity limitation can already be noticed, considering that the largest hubs are growing slower than they could due to capacity bottlenecks in passenger clearance. For example, Deutsche Bank Research mentions that the growth of the world's 10 largest airports was lower than average due to capacity limitations, e.g. at London Heathrow and Frankfurt. This is a clear of indicator how growth is hindered by structural problems, leading to a competitive disadvantage [7].

To solve these issues, USD 31 billion was spent by airports for security and infrastructure investments in $2004^{3)}$. Based on the 2004 figures, a total investment amount of USD 150 billion during the next five years seems to be a realistic forecast.

\section{Challenges for airports and airlines}

What are the challenges that airports will face? First, almost all major airports have announced structural capacity expansions in runways, terminals, etc. as a consequence of the strong growth in number of passengers and volume of cargo [12]. The new infrastructure must enable fast and efficient clearance and ground and flight operations that meet the requirements of airlines and passengers regarding punctuality, comfort and efficiency. In these fields, airports have to operate reliably in very short time spans. Second, the establishment of this infrastructure must be economically reasonable for airports.

\footnotetext{
1) Airports Council International. Annual report 2004, Geneva 2005, p. 3 .

International Air Transport Association. Monthly traffic analysis March 2006, Geneva 2006, p. 1.

3) Airports Council International. Annual Report 2004, Geneva 2005, p. 4.
}

Third, airports have to bear additional costs for the implementation of security requirements that have been established as a reaction to the tightened security situation since 11 September 2001. Although the airport industry has been recovering from the downturn since then, profit margins are decreasing due to increasing security costs ${ }^{3)}$.

For example, the EU Regulation 2320/2002 on common regulations in aviation security requires particular security measures to protect security-restricted areas, causing direct costs at airports [9]. Regulation 2320/2002 defines aviation security as "the combination of measures and human and natural resources intended to safeguard civil aviation against acts of unlawful interference" [10]. Regulation 1138/2004 further defines the critical parts of security-restricted areas at airports [6].

Other issues of concern are infrastructural adaptations to the introduction of wide-bodied aircrafts, particularly the Airbus 380, and the continuing privatization process in the airport industry ${ }^{3)}$.

Table 1 gives an overview of the world's largest airports [1].

Table 1. The world's largest airports in 2005

\begin{tabular}{|c|l|r|}
\hline Rank & \multicolumn{1}{|c|}{ Airport } & Passengers \\
\hline 1 & ATLANTA, GA (ATL) & 85907423 \\
\hline 2 & CHICAGO, IL (ORD) & 76510003 \\
\hline 3 & LONDON, GB (LHR) & 67915389 \\
\hline 4 & TOKYO, JP (HND) & 63282219 \\
\hline 5 & LOS ANGELES, CA (LAX) & 61485269 \\
\hline 6 & DALLAS/FT WORTH AIRPORT, TX (DFW) & 59064360 \\
\hline 7 & PARIS, FR (CDG) & 53756200 \\
\hline 8 & FRANKFURT, DE (FRA) & 52219412 \\
\hline 9 & LAS VEGAS, NV (LAS) & 44280190 \\
\hline 10 & AMSTERDAM, NL (AMS) & 44163098 \\
\hline 11 & DENVER, CO (DEN) & 43307335 \\
\hline 12 & MADRID, ES (MAD) & 41939904 \\
\hline 13 & PHOENIX, AZ (PHX) & 41204071 \\
\hline 14 & BEIJING, CN (PEK) & 40989651 \\
\hline 15 & NEW YORK, NY (JFK) & 40584001 \\
\hline 16 & HONG KONG, CN (HKG) & 40282000 \\
\hline 17 & HOUSTON, TX (IAH) & 39713920 \\
\hline 18 & BANGKOK, TH (BKK) & 38985043 \\
\hline 19 & MINNEAPOLIS/ST PAUL, MN (MSP) & 37563664 \\
\hline 20 & DETROIT, MI (DTW) & 36374906 \\
\hline 21 & ORLANDO, FL (MCO) & 33907396 \\
\hline 22 & SAN FRANCISCO, CA (SFO) & 33580662 \\
\hline 23 & NEWARK, NJ (EWR) & 33033569 \\
\hline 24 & LONDON, GB (LGW) & 32784177 \\
\hline 25 & SINGAPORE, SG (SIN) & 32430856 \\
\hline 26 & TOKYO, JP (NRT) & 31525275 \\
\hline 27 & PHILADELPHIA, PA (PHL) & 31502855 \\
\hline 28 & MIAMI, FL (MIA) & 31008453 \\
\hline 29 & TORONTO, ON, CA (YYZ) & 29289009 \\
\hline 30 & SEATTLE/TACOMA, WA (SEA) & \\
\hline & & \\
\hline
\end{tabular}

Airlines have suffered from the same factors as airports, but in addition to the aspects described above, they have to meet certain specific challenges:

First, rising fuel prices resulted in shrinking margins for airlines and higher ticket prices. Second, many airlines were not prepared for the global rise of new competitors that are absorbing large portions of the new traffic growth and even threaten to take over parts of the established business. These new competitors may be low cost carriers, airlines in western regions, and new players in emerging markets. Consequently, many airlines started restructuring and reorganizing too late. 
Table 2 presents the world's largest airlines [16]. Passenger clearance is one of the processes that are affected the most from those negative developments. The combination of increasing security requirements and scarce terminal resources results in longer departure times for passengers. Although the time passengers spend at airports is growing, passengers cannot use this time because they must undergo additional security checks or have to wait at several points. Punctuality is suffering, and passengers have less time for additional activities at airports like shopping, which is an economic disadvantage for business at airports. Eventually, passenger satisfaction is diminishing because they experience a lack of convenience.

Table 2. The world's largest airlines in 2005

\begin{tabular}{|c|l|r|}
\hline Rank & \multicolumn{1}{|c|}{ Airline } & Passengers in millions \\
\hline 1 & American Airlines, Inc. & 91.570 \\
\hline 2 & Delta Airlines, Inc. & 86.783 \\
\hline 3 & United Airlines & 71.236 \\
\hline 4 & Northwest Airlines, Inc & 56.429 \\
\hline 5 & Japan Airlines International & 51.736 \\
\hline 6 & Deutsche Lufthansa A.G. & 48.268 \\
\hline 7 & All Nippon Airways & 46.450 \\
\hline 8 & Air France & 45.393 \\
\hline 9 & US Airways, Inc & 42.400 \\
\hline 10 & Continental Airlines, Inc. & 40.548 \\
\hline
\end{tabular}

We can summarize that the business of airlines and airports is complex, involves various interest groups, and is embedded in a difficult market situation. Since airlines and airports are also highly vulnerable to external threats, it becomes clear that civil aviation security is a hard challenge for the aviation industry. But attacks on airports and airlines will damage much more than the airport infrastructure alone. Many industries, e.g. logistics, tourism, etc., depend on the on the transport capacities of airports and airlines. Hence, protection of civil aviation means protecting these associated industries as well.

Nevertheless, increasing security regulations result in higher costs and longer transfer times, which may compromise new traffic growth. Moreover, all structural changes either required by law or requested by the market are interlinked to immense costs or investments. Prevention must therefore be the aim of all security activities.

\section{Potential security strategies of airlines and airports}

Having discussed the market and industry situation, we can consider possible strategies to solve the problems described above.

\section{First option: Exploit existing clearance capacities}

Exploiting existing capacities is what many airports and airlines do today. An increasing number of security stops are established in buildings that have not been designed for them, and more passengers are handled within short time slots at the terminals. Alternatively, departures are being rescheduled to early or late times of the day.
This strategy has been proven to work in the short term but implies inconvenience for passengers, who have to wait in long lines at crowded security checks or must depart very early or late. Time for shopping, dining, reading, etc. has diminished, and the number of seats in boarding areas is often inappropriate. Many airports are not even allowed to use early or late departure slots due to the prohibition of night flights. In the long run, this strategy will result in high dissatisfaction of passengers and eventually affect the whole market. Moreover, it will no longer work if passenger numbers rise further. Consequently, airports and airlines have to consider other options.

\section{Second option: Build up new clearance capacities}

Airports usually try to handle long-term growth by enlarging existing structures and building new terminals. Airlines may primarily purchase more airplanes and invest in bigger airplanes such as the A 380 .

Building up new capacities is cost-intensive, diminishes financial results (e.g., investment depreciation), and threatens the competitive position of airports and the affected airlines during the construction time by causing inconvenience for passengers. Furthermore, the construction of new capacities is restricted by official regulations. In many cases, environmental and other societal concerns may also hinder capacity extensions ${ }^{4}$.

To a certain degree, airports and airlines will have to follow this strategy but they may also solve the problem with a more economic and efficient process redesign.

\section{Third option: Redesign security processes}

Pursuing this strategy, airlines and airports optimize existing capacities and processes based on the implementation of innovative technology. Process optimization saves investment costs, enhances convenience for the passenger, and allows airports and airlines to use existing capacities in an optimal way.

Security activities are particularly complex during the passenger clearance process that is conducted by the airlines, airport operators, and border authorities. Security requirements regarding the passenger clearance process are constantly increasing. For example, additional security checks are introduced on the way from check-in to boarding, new detection devices are used at security checks, and additional manual passport controls may take place during boarding. All these activities take extra time, which increases costs and diminishes convenience.

Moreover, public security interests are tied closely to private security interests and responsibilities. Considering the various security activities, sovereign and private responsibilities overlap at airports. Passengers on international, non-Schengen departures run through a series of public and private security control points. For example, security requirements for passengers traveling to the United States who are not US citizens have been constantly increasing. In the passenger clearance process, airlines increasingly take advantage of official travel

\footnotetext{
4) Airports Council International. Annual Report 2004, Geneva 2005, p. 6.
} 
documents, primarily passports. Furthermore, public authorities such as border police often outsource responsibilities at airports to private companies. Both public authorities (e.g., border police) and private actors (e.g., airport security personnel) must rely on each other and cannot accomplish their tasks successfully without each other.

This makes the development of integrated security concepts inevitable. Public and private players can only maintain aviation security with a mix of activities. In the long term, governments, airlines and airports must provide an integrated security approach at air borders and airports to protect a country's security. Moreover, a single incident may damage tourism and trade for a long time. This integrated approach must focus on the passenger clearance process and include all process steps from check-in, security checks, and boarding to arrival. Furthermore, the process must be interoperable for all airlines, airports and other participants involved.

Consequently, airports and airlines have to consider process optimization in addition to or as a substitution for capacity extensions. Rather than spending money to extend structural and manpower capacities, airlines and airports may invest in process optimizations. New technologies like biometrics and applications based on these technologies will enable change management. Particularly, the integration of biometrics into travel documents such as passports and the close connection of aviation security to border control will trigger optimization.

In reality, airports and airlines should pursue a mixture of the second and the third strategy. The expected market growth will to a certain degree require structural extensions, but they can be kept as low as possible with redesigned processes.

Any solution has to meet three core requirements:

- Security is the basis for passenger trust and, eventually, the basis of the civil aviation industry's economic success.

- Convenience must be provided through speed and efficiency of passenger clearance and may be a Unique Selling Proposition in times of increasing competition.

- Cost efficiency means that the costs of the biometric solution must be lower than structural capacity extensions and additional manpower.

Although both public authorities and private institutions are interested in maintaining and enhancing the security level in civil aviation, public authorities may put more emphasis on high security. Airlines and, in many cases, airports as profit-oriented institutions have to find an optimal solution from the cost efficiency perspective as well. From the marketing perspective, airports and airlines must offer convenient processes to their passengers to prevent competitive disadvantages.

These circumstances represent the window of opportunity for security providers, whose products and solutions are suited to enable airlines and airports to design their processes more quickly, securely, efficiently and comfortably. Their task is to research, develop and implement products and solutions that meet these core needs. Technology-based solutions may be the starting point for a redesigned passenger clearance process.

\section{Biometric technologies in civil aviation security}

Biometric technologies are concerned with the measurement and evaluation of human physiological or behavioral data. The term biometrics derives from the Greek words "bios" (life) and "metron" (measure). In a broader sense, biometrics can be defined as the measurement of body characteristics, in other words, biological statistics [15]. With this meaning the term has been used in medicine, biology, agriculture and pharmacy. Criminal prosecution, identity management and police records have used pictures, body height and finger prints for a long time [2]. However, the rise of new technologies to measure and evaluate physical or behavioral characteristics of living organisms has automatically given the word a second meaning. Research on computer-based, automated recognition of physiological and behavioral characteristics started in the 1960s, and the first commercial application was installed in 1968 [3]. In the present article, the term "biometric technologies" refers to automated methods of recognizing a person based on physiological or behavioral characteristics [8].

Automated systems based on biometrics to recognize persons enable fast, user-friendly and highly secure identification and verification processes. Among the most-used biometric technologies are facial, fingerprint, iris, signature and voice recognition [4]. Since biometric methods take advantage of individual human characteristics, they are more reliable than other methods of authorization that are only based on knowledge or possession, e.g. PINs.

In recent years, the security-oriented use of biometric technologies has become a promising field of research. Particularly, the verification and identification of people based on these characteristics have turned out to be the most important application of biometrics. Public security has been in the center of interest since 2001, and the deployment of biometrics to machine readable travel documents such as passports triggers the worldwide demand for biometric technologies. Citizens see the first large-scale applications related to identification documents such as electronic passports an ID cards. These projects will function as pioneer projects and market openers for additional applications and process optimizations.

According to J. Ringbeck, R. Hauser the use of biometric security technology in airport security areas allows high optimization of existing processes [17]. Although this optimization approach is a hard challenge considering the various interest groups in civil aviation security (e.g. airports, airlines, border police, security companies), it is supported by the success of biometric passports and other travel documents. Once sovereign border control at airports has introduced processes based on electronic passports and biometric technologies, 
private sector applications in the civil aviation business will profit from these pioneer applications.

Civil aviation security will be among the application fields of biometrics that profit the most from pioneer projects in the field of border security. Private parties such as airports and airlines are likely to redesign their processes alike, and establish related applications. Unlike land border control points, air border control points are not located at a country's geographical border but right at the airports. Therefore, border security at airports correlates with airport and airline security. For example, if biometric passports redefine the border control processes in the near-term future, in the mid-term, biometric aviation security will profit from the new border control processes. Since biometric methods only work in combination with other technologies such as document reading devices, RFID, optics and structural security measures, the traditional processes in these areas will change dramatically.

For the past few years, several trials have demonstrated the technical possibility to automate border control processes with biometric technologies, e.g. BioP II in Frankfurt, Germany [5]. Only a few trials were started with a focus to aviation processes, however. Even those aviation trials mostly put emphasis on employee access to security-restricted areas. Although this is one part of civil aviation security, it does not involve passengers and therefore does not solve the primary problems of airports and airlines related to limited terminal resources. Biometric access control for employees and visitors is much easier than biometric passenger clearance because the first group is smaller and changes less frequently.

Summarizing the current status of existing biometric approaches in civil aviation security, we have to state that most of these approaches:

- Focus on employees and visitors

- Focus on single process steps such as fast access to security areas

- Are based on one-stop solutions that do not include either transfer or arrival processes

- Are based on additional storage mediums such as trusted traveler smart cards but do not yet take advantage of biometric travel documents like electronic passports

- Require prior enrolment to obtain the biometric reference data

- Can only be fully used by travelers with hand luggage

- Are one-partner solutions. Inter-airline and inter-airport processes have hardly been considered

- Do not evaluate web and mobile check-in

- Do not include booking processes

Even if single aspects of this list are part of a trial, they are not part of an integrated concept. Normally, these trials take advantage of existing frequent flyer programs. Frequent flyers can enroll their data and receive a biometric storage medium, e.g. a smart card. These trials may re-establish comfort for these customers but do not solve the problems of the majority of passengers who are not frequent flyers.
So far there is no civil aviation security program that uses biometric technologies based on electronic travel documents, including all process steps from booking, check-in, security controls and boarding to arrival. Integration of existing aviation IT infrastructures and an integrated real life use for international flights will be even more difficult to realize.

Figure illustrates the potential application fields of biometrics in civil aviation security.

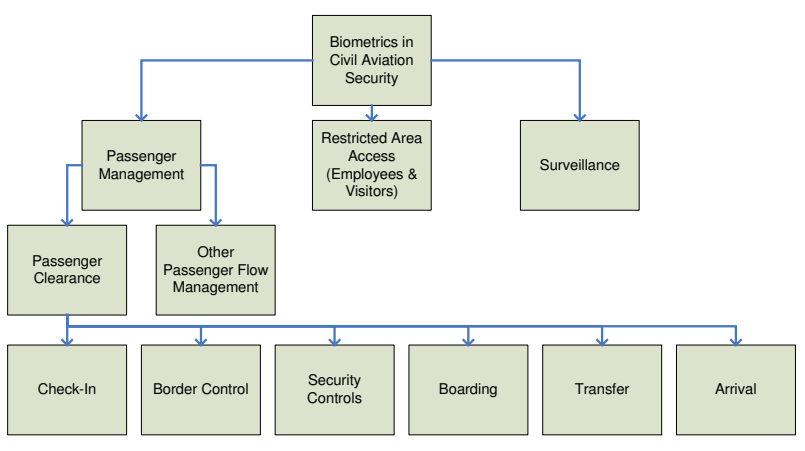

Biometric application fields in civil aviation security

\section{Perspectives}

We have seen that airports and airlines face several challenges that result from changes in their strategic environment, market, and industry. Increasing security requirements are one of the reasons for this development. In combination with growing passenger numbers and increasingly competitive pressure, security requirements have negative effects on the economic and competitive position of airports and airlines.

Currently, airports and airlines counteract this development by exploiting existing capacities, allocating more manpower and investing in additional terminal and clearance infrastructure. Eventually, these activities will further decrease margins and diminish passenger convenience.

Integrated security process optimization based on biometric technologies enables the harmonization, simplification, linkage and automation of elements of the passenger clearance process and other fields of application in civil aviation security. Passenger clearance is an application field of biometrics that has not yet been evaluated and tested in detail due to its complexity but allows high process optimization potential and, therefore, financial relief for airports and airlines.

This approach provides the key to economic success, enhances passenger convenience, minimizes the necessary additional infrastructure investments, and establishes solutions that are forward-looking. Passengerfriendly security processes may even be a unique selling proposition and an additional value for airports and airlines in competition.

In the long term, passenger clearance and other processes in civil aviation security will profit from the deployment of biometrics to passports and visas. Eventually, biometrics will penetrate all processes related 
to identification and verification of human beings in civil aviation security.

The author's future research will address the following issues:

- Detailed analysis of passenger clearing processes

- Assessment of the process bottlenecks and limitations

- Identification of potential approaches to remedy these bottlenecks and limitations

- Definition and implementation of an integrated and automated passenger clearance process including all process steps from booking to arrival

- Solution design depending on the clearance process chain

- Implementation and evaluation of large-scale biometric security solutions in civil aviation security

Nevertheless, biometric technologies will only be the enabler of process optimization. They may provide the technological basis for process optimizations but will not substitute integrated security concepts and planning.

\section{Conclusions}

As a result of the previous analysis, we see that the future passenger clearance process should be based on the use of machine-readable passports that include electronic storage mediums and biometric data. An integrated civil aviation security approach should meet the following requirements:

- Compliance with the core needs of airlines and airports: High security, high convenience, and low costs

- Focus on passenger processes and optimization of the clearance process

- Focus on biometric technologies to identify and verify passengers

- Usage of biometric travel documents, particularly the electronic passport

- Integration of biometric check-in and boarding

- Integration of existing aviation processes and infrastructure

- Compliance with IATA strategies and key projects such as eTicketing and RFID-based baggage handling

- Interoperability for all airlines and airports

- Standardization and harmonization on an international level (ICAO, ISO, ACI, IATA)

\section{References}

1. Airports Council International. Passenger Traffic 2005. Preliminary. In http://www.airports. org/cda/aci/display/main/aci_content.jsp?zn=aci $\& \mathrm{cp}=1-5-54 \_9 \_2$, download 2006-06-12.

2. ALBRECHT, APT. Bedeutung der politischen und rechtlichen rahmenbedingungen für biometrische identifikationssysteme. In BEHRENS, MRR. Biometrische identifikation; grundlagen, verfahren, perspektiven, verlag vieweg. Braunschweig/ Wiesbaden, 2001, s. 31.
3. AMBERG, M. et al. Biometrische verfahren. Studie zum state of the art, Friedrich-AlexanderUniversity Erlangen-Nuremberg Erlangen. Nuremberg, 2003, p. 5.

4. BIOVISION Consortium. Roadmap for biometrics in Europe to 2010. Roadmap to successful deployment from the user and system integrator perspective. Ipswich, 2003, p. 19.

5. Bundespolizei. Pilotprojekt "Automatisierte und biometriegestützte grenzkontrolle". In http://www.bundespolizei.de/cln_030/nn_48520 8/sid_32C6E8386708A61019F2D3E06E0A1195 /DE/Home/Automatisierte_Grenzkontrolle/info rmationenVerfahrensablauf.html_nnn=true, download 10 June, 2006.

6. Commission of the European Communities. Commission regulation (EC) No 1138/2004 of 21 June 2004 establishing a common definition of critical parts of security restricted areas at airports. Official Journal of the European Communities, Brussels, 2004-06-22, L 221/6-7.

7. Deutsche Bank Research. Große airports verlieren 2005 an Boden. In http://www.dbresearch.com/servlet/reweb2.ReW E, download 2006-06-12.

8. European Biometric Forum. Biometrics lexicon. In http://www.eubiometricforum.com/index.php $?$ option $=$ content $\&$ task $=$ view $\& i d=29 \&$ Itemid $=$ 46.

9. European Parliament and Council. Regulation (EC) No 2320/2002 of the European Parliament and of the Council of 16 December 2002; Establishing common rules in the field of civil aviation security. Official Journal of the European Communities, Brussels, 2002-12-30, L 355/1-21.

10. European Parliament and Council. Regulation (EC) No 2320/2002 of the European Parliament and of the Council of 16 December 2002. Establishing common rules in the field of civil aviation security. Official Journal of the European Communities, Brussels, 2002-12-30, L 355/1-21, p. 2.

11. HEYMANN, E. Zukunft der drehkreuzstrategie im luftverkehr. In Deutsche Bank Research. Aktuelle Themen 354, 2006-05-30, s. 4.

12. HEYMANN, E. Zukunft der Drehkreuzstrategie im Luftverkehr. In Deutsche Bank Research. Aktuelle Themen 354, 2006-05-30, s 5.

13. HEYMANN, E. Zukunft der Drehkreuzstrategie im Luftverkehr. In Deutsche Bank Research Aktuelle Themen 354, 2006-05-30, s. 4 f.

14. International Air Transport Association. Industry Outlook March 2006. New financial forecast. In http://www.iata.org/NR/rdonlyres/DA8ACB38676F-4DB1-A2AC-4CB2C/0/Industry_Outlook _Mar06.pdf, download 2006-05-05.

15. NOLDE, V. Grundlegende aspekte biometrischer verfahren. In Biometrische verfahren, fachverlag Deutscher wirtschafts- 
dienst. Edited by V. Nolde and L. Leger. Cologne, 2002, s. 20, download 2006-05-08.

16. RINGBECK, J.; HAUSER, R. et al. „Aero“dynamik im europäischen flughafensektor. In Neuausrichtung wegen veränderter nachfrage und kostendruck erforderlich. Edited by BA. Hamilton. 2005, s. 1.

17. RINGBECK, J.; HAUSER, R. et al. „Aero“dynamik im europäischen flughafensektor. In Neuausrichtung wegen veränderter nachfrage und kostendruck erforderlich. Edited by BA. Hamilton. 2005, s. 13. 